\title{
Mechanism and Physiologic Significance of the Suppression of Cholesterol Esterification in Human Interstitial Fluid
}

\author{
Norman E. Miller ${ }^{*}$, Waldemar L. Olszewski², Irina P. Miller ${ }^{3}$ and Mahmud N. Nanjee ${ }^{4}$
}

${ }^{1}$ Magdalen College, University of Oxford, Oxford, UK, ${ }^{2}$ Department of Surgical Research and Transplantology, Medical Research Centre, Polish Academy of Sciences, Warsaw, Poland, ${ }^{3}$ Department of Cardiovascular Biochemistry, Queen Mary University of London, London, UK, ${ }^{4}$ Cardiovascular Genetics Unit, School of Medicine, University of Utah, Salt Lake City, UT, USA

OPEN ACCESS

Edited by:

Ajay Sharma,

Chapman University School of Pharmacy, USA

Reviewed by: Gian Marco Leggio,

University of Catania, Italy

Nadezhda A. German,

Texas Tech University Health Science

Center, USA

*Correspondence:

Norman E. Miller

n.e.miller@btinternet.com

Specialty section:

This article was submitted to Experimental Pharmacology and Drug

Discovery,

a section of the journal

Frontiers in Pharmacology

Received: 19 April 2016

Accepted: 05 July 2016

Published: 15 July 2016

Citation:

Miller NE, Olszewski WL, Miller IP and Nanjee MN (2016) Mechanism and Physiologic Significance of the

Suppression of Cholesterol

Esterification in Human Interstitial

Fluid. Front. Pharmacol. 7:216.

doi: 10.3389/fphar.2016.00216
Cholesterol esterification in high density lipoproteins (HDLs) by lecithin:cholesterol acyltransferase (LCAT) promotes unesterified cholesterol (UC) transfer from red cell membranes to plasma in vitro. However, it does not explain the transfer of UC from most peripheral cells to interstitial fluid in vivo, as HDLs in afferent peripheral lymph are enriched in UC. Having already reported that the endogenous cholesterol esterification rate (ECER) in lymph is only $5 \%$ of that in plasma, we have now explored the underlying mechanism. In peripheral lymph from 20 healthy men, LCAT concentration, LCAT activity (assayed using an optimized substrate), and LCAT specific activity averaged, respectively, $11.8,10.3$, and $84.9 \%$ of plasma values. When recombinant human LCAT was added to lymph, the increments in enzyme activity were similar to those when LCAT was added to plasma. Addition of apolipoprotein Al (apo Al), fatty acid-free albumin, Intralipid, or the $d<1.006 \mathrm{~g} / \mathrm{ml}$ plasma fraction had no effect on ECER. During incubation of lymph plus plasma, the ECER was similar to that observed with buffer plus plasma. When lymph was added to heat-inactivated plasma, the ECER was 11-fold greater than with lymph plus buffer. Addition of discoidal proteoliposomes of apo Al and phosphatidycholine (PC) to lymph increased ECER 10-fold, while addition of apo $\mathrm{Al} / \mathrm{PC} / \mathrm{UC}$ disks did so by only six-fold. We conclude that the low ECER in lymph is due to a property of the HDLs, seemingly substrate inhibition of LCAT by excess cell-derived UC. This is reversed when lymph enters plasma, consequent upon redistribution of UC from lymph HDLs to plasma lipoproteins.

Keywords: apolipoprotein Al, lecithin:cholesterol acyltransferase, high density lipoproteins, lymph, interstitial fluid

\section{INTRODUCTION}

Glomset et al. (1966) showed that the unesterified cholesterol (UC) of high density lipoproteins (HDLs) is the optimum physiologic substrate for lecithin:cholesterol acyltransferase (LCAT) in plasma. He also showed that cholesterol esterification in HDLs promotes the transfer of UC from red cell membranes to plasma HDLs in vitro (Glomset, 1970; Glomset and Norum, 1973). On this basis, he hypothesized that the HDL-LCAT system provides the mechanism by which UC is 
drawn from peripheral cells to HDLs for delivery to the liver and subsequent elimination. However, later observations seemed to conflict with this concept. In humans and mice with genetic LCAT deficiencies, for example, excess cholesterol was found to be restricted to specific sites, including red blood cells, renal glomeruli, and the spleen (Stokke et al., 1974; Lambert et al., 2001). Based on studies in transgenic mice, Alam et al. (2001) and Tanigawa et al. (2009) concluded that variations in LCAT gene expression had little or no effect on reverse cholesterol transport. Reports that the rate of esterification of UC is much lower in peripheral lymph than in plasma (Dory et al., 1983; Miller et al., 2013) also questioned the role of LCAT in cholesterol removal from most cells. Confirmation that LCAT cannot be rate-limiting was provided by demonstrations that the UC/CE ratio in lymph HDLs exceeds that in plasma HDLs (Reichl et al., 1980; Nanjee et al., 2000b), and that the former include disks devoid of core lipids (Nanjee et al., 2001) similar to those seen in the plasma of LCAT-deficient subjects (Glomset et al., 1980). While this line of research was progressing, others discovered the role of ABCA1 transporters in mediating the egress of UC from cells to lipid-poor apo AI particles (Oram and Heinecke, 2005).

The explanation of the profound suppression of cholesterol esterification in HDLs once they have transferred from plasma across endothelium into the interstitial fluid is not known. Apolipoprotein (apo) AI, the principal cofactor of LCAT (Fielding et al., 1972), has been shown to be present at a concentration of about one fifth that in plasma (Nanjee et al., 2000b), but there are no published data on LCAT concentration in lymph. The UC in discoidal HDLs isolated from the plasma of subjects with familial LCAT deficiency is an efficient substrate for the enzyme (Glomset et al., 1970). This is also true of UC acquired by reconstituted HDL disks composed of phosphatidylcholine (PC) and human apo AI (Nanjee et al., 1999), and of the UC in HDL disks recovered from rat liver perfusates (Hamilton et al., 1976). When infused intravenously into humans, apo AI/PC disks acquire UC and are rapidly converted to CE-rich spheroidal HDLs (Nanjee et al., 1999). And yet the discoidal HDLs formed in interstitial fluid do not undergo such metabolism until after they have entered the blood.

An understanding of the mechanism of the suppression of cholesterol esterification in interstitial fluid may shed light on the regulation of LCAT, and aid the development of new approaches to the prevention of atherosclerosis by modulation of $\mathrm{HDL}$ metabolism. In this the first study of the mechanism in humans, we have tested several hypotheses by experiments in vitro with normal human afferent lymph, which is representative of interstitial fluid (Nanjee et al., 2000b, 2001).

\section{MATERIALS AND METHODS}

\section{Subjects}

Lymph from 20 healthy men was studied. Ages were 20-69 years (mean, 34.5 years), body weights $60-97 \mathrm{~kg}$ (75 kg), body mass indexes $19.3-28.4 \mathrm{~kg} / \mathrm{m}^{2}\left(23.5 \mathrm{~kg} / \mathrm{m}^{2}\right)$, plasma total cholesterol 1.54-5.48 $\mathrm{mmol} / \mathrm{l}(4.16 \mathrm{mmol} / \mathrm{l})$, plasma HDL cholesterol
0.71-1.89 $\mathrm{mmol} / \mathrm{l}(1.22 \mathrm{mmol} / \mathrm{l})$, and plasma triglycerides $0.74-$ $3.26 \mathrm{mmol} / \mathrm{l}(1.36 \mathrm{mmol} / \mathrm{l})$. Screening of the volunteers for health status was as previously described (Nanjee et al., 2000b). All subjects gave informed consent. The protocol had been approved by the ethics committees of London Bridge Hospital and St Bartholomew's Hospital Medical School, London, where the clinical and laboratory procedures were performed, respectively. All subjects gave written informed consent.

\section{Clinical Procedures}

Interstitial fluid was collected as afferent (pre-nodal) peripheral lymph from overnight-fasted subjects under metabolic ward conditions by cannulation of a lymph vessel in the lower leg, according to our previously described procedures (Nanjee et al., 2000b). Lymph was collected for periods of 2 or $3 \mathrm{~h}$ into plastic tubes containing $2 \mathrm{mg}$ dry disodium EDTA (Nanjee et al., $2000 \mathrm{~b}$ ). Flow rates were $0.10-2.0 \mathrm{ml} / \mathrm{h}$ (mean 0.78 ). Preliminary studies had shown that collection into tubes containing an LCAT inhibitor, or collection into tubes chilled in crushed ice, had no effect on the UC/CE ratios of the samples (Nanjee et al., 2000b; Cooke et al., 2004), indicating there was essentially no esterification of cholesterol during the collection period. Venous blood samples were collected into disodium EDTA $(1 \mathrm{mg} / \mathrm{ml})$ at the mid-point of each lymph collection period, and placed into crushed ice.

\section{Laboratory Procedures}

Blood and lymph samples were centrifuged immediately after collection, as previously described (Nanjee et al., 2000b). The supernatants were divided into aliquots, which were flash frozen in liquid nitrogen, and then transferred to a freezer at $-85^{\circ} \mathrm{C}$. All assays were performed in duplicate, and the mean result calculated. The details of the laboratory procedures used in each experiment are provided as footnotes to the figures and table.

\section{RESULTS}

\section{Endogenous Cholesterol Esterification Rate}

In conformity with previous studies, the endogenous cholesterol esterification rate (ECER) in lymph during incubation in vitro averaged only $4.2 \%(P<0.001)$ of that in plasma from the same subjects (Table 1). The rate was not correlated with lymph LCAT concentration $(r=+0.06)$, lymph LCAT activity $(r=-0.02)$, or lymph apo AI concentration $(r=+0.02)$.

\section{LCAT Activity}

LCAT activity in lymph assayed using a radio-labeled proteoliposome substrate averaged $10.3 \%(P<0.01)$ of that in plasma (Table 1). It was positively correlated with both lymph LCAT concentration $(r=+0.93, P<0.001$; Figure 1) and lymph apo AI concentration $(r=+0.83, P<0.001)$, but not with plasma LCAT activity $(r=+0.12)$. The correlation coefficient between plasma LCAT activity and plasma LCAT concentration was $+0.78(P<0.001 ;$ Figure 1$)$. 
TABLE 1 | Endogenous esterification rate, LCAT activity, LCAT concentration, LCAT specific activity, and apo Al concentration in lymph and plasma samples from twenty healthy male subjects.

\begin{tabular}{|c|c|c|c|c|c|c|c|c|c|c|c|c|}
\hline \multirow[b]{2}{*}{ Subject } & \multicolumn{2}{|c|}{$\begin{array}{l}\text { LCAT conc }^{1} \\
\qquad(\mu \mathrm{g} / \mathrm{ml})\end{array}$} & \multicolumn{2}{|c|}{$\begin{array}{c}\text { ECER }^{2} \\
(\mathrm{nmol} / \mathrm{ml} / \mathrm{h})\end{array}$} & \multicolumn{2}{|c|}{$\begin{array}{l}\text { LCAT activity }^{3} \\
\text { (nmol/ml/h) }\end{array}$} & \multicolumn{2}{|c|}{$\begin{array}{l}\text { LCAT sp activity } \\
\text { (nmol/h/ } / \mu \mathrm{g})\end{array}$} & \multicolumn{2}{|c|}{$\begin{array}{c}\text { Apo Al conc }{ }^{5} \\
(\mathrm{mg} / \mathrm{ml})\end{array}$} & \multicolumn{2}{|c|}{$\begin{array}{l}\text { UC conc } \\
\text { ( } \mathrm{mmol} / \mathrm{l})\end{array}$} \\
\hline & Lymph & Plasma & Lymph & Plasma & Lymph & Plasma & Lymph & Plasma & Lymph & Plasma & Lymph & Plasma \\
\hline 1 & 0.84 & 5.24 & 2.13 & 69.6 & 13.5 & 103 & 16.1 & 19.7 & 0.24 & 1.02 & 0.13 & 1.17 \\
\hline 2 & 0.71 & 6.46 & 3.70 & 69.3 & 12.8 & 126 & 18.0 & 19.5 & 0.19 & 0.85 & 0.05 & 1.02 \\
\hline 3 & 1.06 & 6.20 & 2.01 & 37.6 & 20.4 & 119 & 19.2 & 19.2 & 0.32 & 1.19 & 0.14 & 1.01 \\
\hline 4 & 0.54 & 6.26 & 2.62 & 57.0 & 10.4 & 132 & $\underline{19.3}$ & $\underline{21.1}$ & 0.13 & $\underline{0.77}$ & 0.06 & 1.06 \\
\hline 5 & 0.58 & 6.05 & 1.27 & 48.2 & 7.40 & 104 & 12.8 & 17.2 & 0.17 & 0.86 & 0.05 & 0.86 \\
\hline 6 & 1.08 & 7.08 & 2.26 & 44.7 & 14.9 & 105 & 13.8 & 14.9 & 0.19 & 0.82 & 0.08 & $\underline{0.80}$ \\
\hline 7 & 0.76 & 8.62 & 3.52 & 68.5 & 10.1 & 141 & 13.3 & 16.4 & 0.20 & 1.29 & 0.10 & 1.30 \\
\hline 8 & 0.96 & 8.55 & 3.62 & $\underline{83.3}$ & 12.0 & 133 & 12.5 & 15.5 & 0.23 & 0.87 & 0.10 & 1.16 \\
\hline 9 & 1.32 & 8.19 & 4.60 & 46.1 & 20.9 & 155 & 15.8 & 18.9 & 0.30 & 0.97 & 0.09 & 0.90 \\
\hline 10 & 0.68 & 6.34 & 4.19 & 70.6 & 7.30 & 131 & $\underline{10.7}$ & 20.7 & 0.17 & 0.99 & 0.07 & 0.94 \\
\hline 11 & $\underline{0.37}$ & 6.86 & 2.88 & 57.3 & $\underline{5.00}$ & 125 & 13.5 & 18.3 & $\underline{0.09}$ & 0.90 & $\underline{0.04}$ & 1.04 \\
\hline 12 & 1.32 & 7.42 & 1.77 & 58.4 & 23.8 & 132 & 18.0 & 17.8 & 0.33 & 1.18 & 0.11 & 0.89 \\
\hline 13 & 0.84 & 6.99 & 1.54 & 57.0 & 13.5 & 129 & 16.1 & 18.4 & 0.17 & 0.81 & 0.13 & 1.11 \\
\hline 14 & 0.74 & 8.78 & 2.28 & 65.2 & 11.2 & $\underline{179}$ & 15.1 & 20.3 & 0.28 & 1.51 & 0.07 & 1.05 \\
\hline 15 & $\underline{1.66}$ & 7.91 & 3.16 & 66.4 & $\underline{24.2}$ & 141 & 14.6 & 17.8 & $\underline{0.34}$ & 0.91 & $\underline{0.23}$ & 1.08 \\
\hline 16 & 0.61 & $\underline{4.95}$ & 1.38 & 52.3 & 10.3 & $\underline{96}$ & 16.9 & 19.4 & 0.16 & 0.78 & 0.07 & 0.94 \\
\hline 17 & 0.71 & $\underline{10.9}$ & 1.25 & 68.6 & 8.90 & 154 & 12.5 & $\underline{14.2}$ & 0.13 & 0.87 & 0.05 & 1.31 \\
\hline 18 & 0.79 & 7.96 & $\underline{5.10}$ & 79.3 & 10.9 & 142 & 13.8 & 17.8 & 0.28 & $\underline{1.62}$ & 0.10 & $\underline{1.63}$ \\
\hline 19 & 0.88 & 8.98 & 2.93 & 76.4 & 15.0 & 146 & 17.0 & 16.3 & 0.26 & 1.47 & 0.13 & 1.30 \\
\hline 20 & 1.21 & 8.86 & $\underline{1.04}$ & 77.1 & 17.1 & 134 & 14.1 & 15.1 & 0.24 & 1.05 & 0.07 & 0.87 \\
\hline Mean & 0.88 & 7.43 & 2.66 & 62.6 & 13.5 & 131 & 15.2 & 17.9 & 0.22 & 1.04 & 0.09 & 1.07 \\
\hline$S D$ & 0.31 & 1.46 & 1.18 & 12.6 & 5.41 & 20 & 2.4 & 2.0 & 0.07 & 0.20 & 0.04 & 0.20 \\
\hline
\end{tabular}

${ }^{1}$ LCAT concentration was measured using an ELISA kit provided by Daiichi Pure Chemicals, Japan, according to the procedures described by Kobori et al. (2002). ${ }^{2}$ For measurement of ECER, paired samples of plasma and lymph were incubated in vitro either in crushed ice or at $37^{\circ} \mathrm{C}$ for $3 \mathrm{~h}$, and then rapidly cooled to $0-4^{\circ} \mathrm{C}$ in crushed ice. The rate of esterification of cholesterol was calculated from the decrease in the concentration of UC (Albers et al., 1986) measured enzymatically (Nanjee and Miller, 1996). ${ }^{3}$ LCAT activity was measured using an optimal proteoliposome substrate of apo Al, PC and ${ }^{14}$ [C]-labeled UC (molar ratio 1:300:10; Albers et al., 1986).

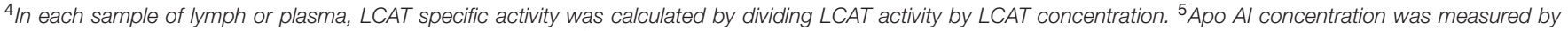

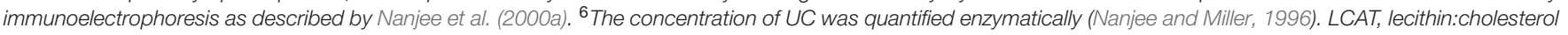

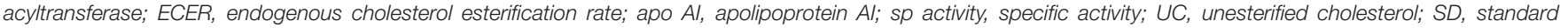
deviation. The values underlined are the highest and lowest in each column.

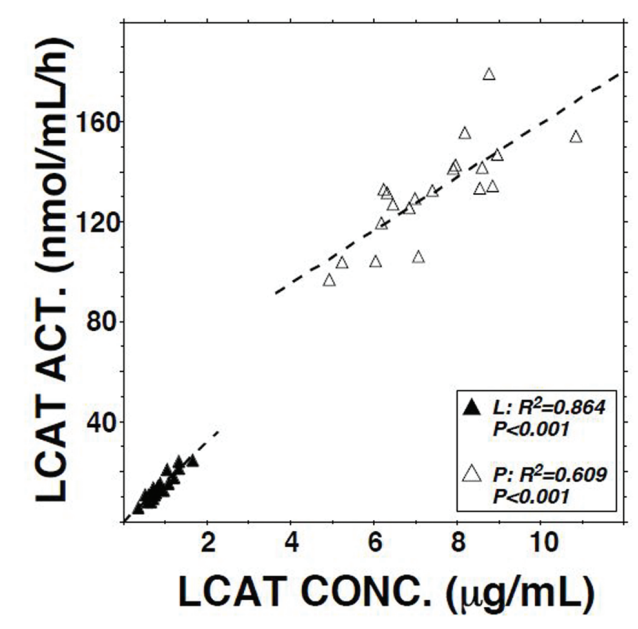

FIGURE 1 | Relation of LCAT activity to LCAT concentration in plasma and lymph samples from 20 subjects. Assays were performed as described in Table 1.

\section{LCAT Concentration}

Lymph LCAT concentration averaged $11.8 \%(P<0.01)$ of plasma LCAT concentration (Table 1). It was not significantly correlated with plasma LCAT concentration $(r=+0.26, P=0.27)$, but was correlated with lymph apo AI concentration $(r=+0.80$, $P<0.001)$.

\section{Specific Activity of LCAT}

The specific activities of LCAT in lymph and plasma were calculated by dividing the result obtained for LCAT activity by that for LCAT concentration in the same sample. On average, the specific activity in lymph was slightly lower than that in plasma $(P<0.001$; Table 1$)$.

\section{Apo Al and UC Concentrations}

In agreement with previous studies, lymph apo AI concentration averaged about $21 \%$ of plasma apo AI concentration $(P<0.001$; Table 1). The two were positively correlated $(r=+0.54$, $P=0.013)$. The concentration of UC in lymph averaged $8.4 \%$ $(P<0.001)$ of that in plasma (Table 1). 


\section{Effect on ECER of Mixing Lymph with Native or Heat-Inactivated Plasma}

The ECER observed with various mixtures of lymph, buffer, buffer containing fatty acid-free albumin, native human plasma, and heat-inactivated human plasma are presented in Figure 2. The result obtained with a mixture of lymph and native plasma was essentially identical to that obtained with a mixture of similar volumes of buffer and native plasma, providing evidence that lymph does not contain a soluble inhibitor of cholesterol esterification. The ECER observed during incubation of lymph with heat-inactivated human plasma (i.e., in which LCAT had been inactivated by incubation for $30 \mathrm{~min}$ at $56^{\circ} \mathrm{C}$, ref 20) was 11 fold greater than that observed with a mixture of similar volumes of lymph and buffer, demonstrating that the enzyme in lymph was functional and able to catalyze the esterification of UC in plasma HDLs. In the same series of incubations, addition of fatty acid-free albumin had no effect on the ECER in lymph (Figure 2).

\section{Effect of Adding Recombinant Human LCAT}

When increasing amounts of recombinant human LCAT were added to lymph, a linear increase in LCAT activity was recorded (Figure 3). The slopes of the regression lines were similar to those observed when LCAT was added to buffer, normal plasma, plasma from a subject with familial LCAT deficiency (Nanjee et al., 2003), or heat-inactivated plasma.

\section{Effect on ECER of Triglyceride-Rich Lipoproteins}

We have reported that human lymph contains both $\mathrm{CE}$ transfer protein (CETP) and CETP activity (Miller et al., 2013). The principal recipient particles for cholesteryl esters (CEs) transferred from HDLs by CETP in plasma are triglyceriderich lipoproteins (TGRLs) and low density lipoproteins (LDLs; Fielding and Fielding, 1981). As LCAT activity is inhibited by CEs (Chajek et al., 1980), and lymph contains almost no TGRLs and few LDLs (Nanjee et al., 2000b, 2001), we tested the hypothesis that LCAT in lymph is inhibited as a consequence of retention of CEs in spheroidal HDLs. However, addition of neither the $d<1.006 \mathrm{~g} / \mathrm{ml}$ fraction of normal human plasma nor Intralipid $20 \%$ increased the ECER (Figure 4).

\section{Effects of Adding Lipid-Free Apo Al, Apo Al/PC disks, or Apo Al/PC/UC disks}

Addition of delipidated human apo AI to lymph had no effect on the ECER (Figure 5). By contrast, addition of discoidal proteoliposomes composed of human apo AI in association with PC increased the ECER during the first $2 \mathrm{~h}$ of incubation by 10 fold (Figure 5). When similar incubations were carried out using disks containing UC in addition to apo AI and PC, the ECER was increased by only 6-fold (Figure 5).

\section{DISCUSSION}

This is the first study of the mechanism underlying the very low rate of cholesterol esterification in human interstitial fluid relative to plasma. We found that afferent lymph, which is representative of interstitial fluid (Michel and Curry, 1999; Nanjee et al., 2000b, 2001), contains active LCAT enzyme. As expected, LCAT concentration was much lower than in plasma. Nevertheless, when lymph was added to heatinactivated plasma, the enzyme catalyzed the esterification of $\mathrm{UC}$ at a rate of more than 10-fold that in lymph alone,

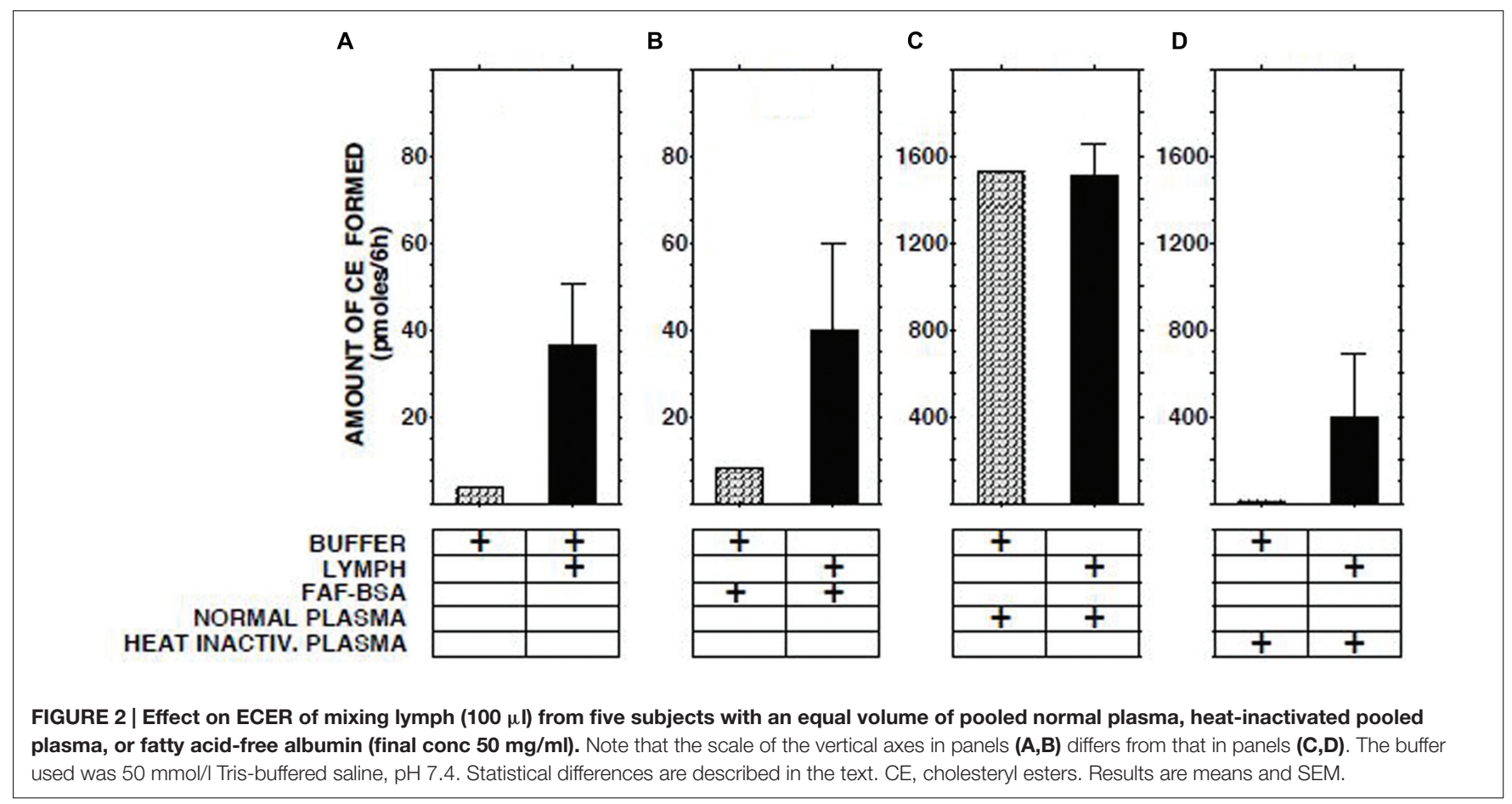




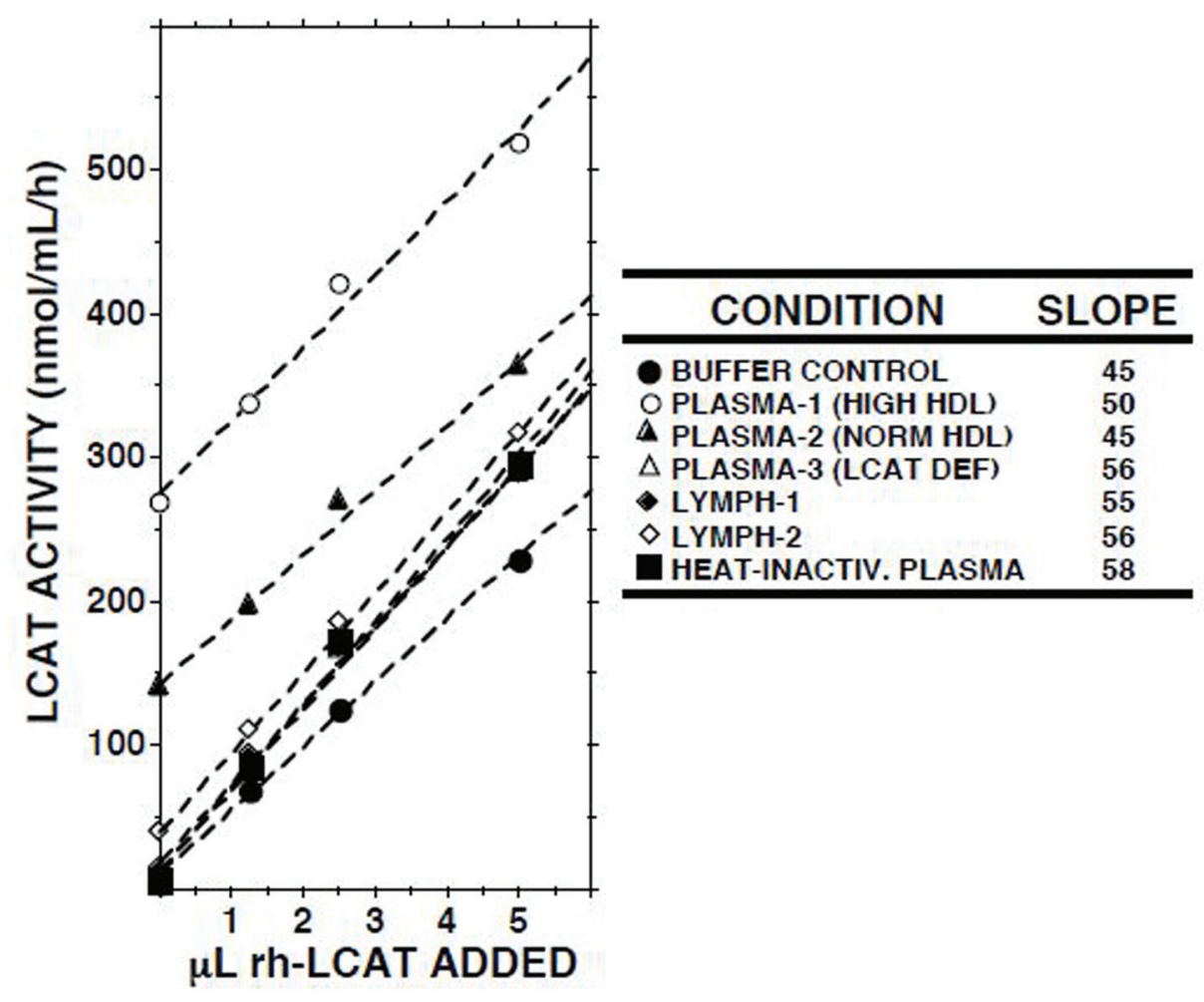

FIGURE 3 | Effects of adding recombinant human LCAT (rh-LCAT; $12.5 \mu \mathrm{l}$ ) on LCAT activity in samples of plasma and lymph from subjects with normal and high HDL cholesterol concentrations, plasma from a subject with familial LCAT deficiency (Nanjee et al., 2003), plasma in which LCAT had been heat-inactivated $\left(30 \mathrm{~min}\right.$ at $\left.56^{\circ} \mathbf{C}\right)$, and Tris-buffered saline, pH 7.4. LCAT activity was measured as described in the footnote to Table $\mathbf{1}$. Human rh-LCAT was a generous gift from Dr John Parks (Miller et al., 1996).

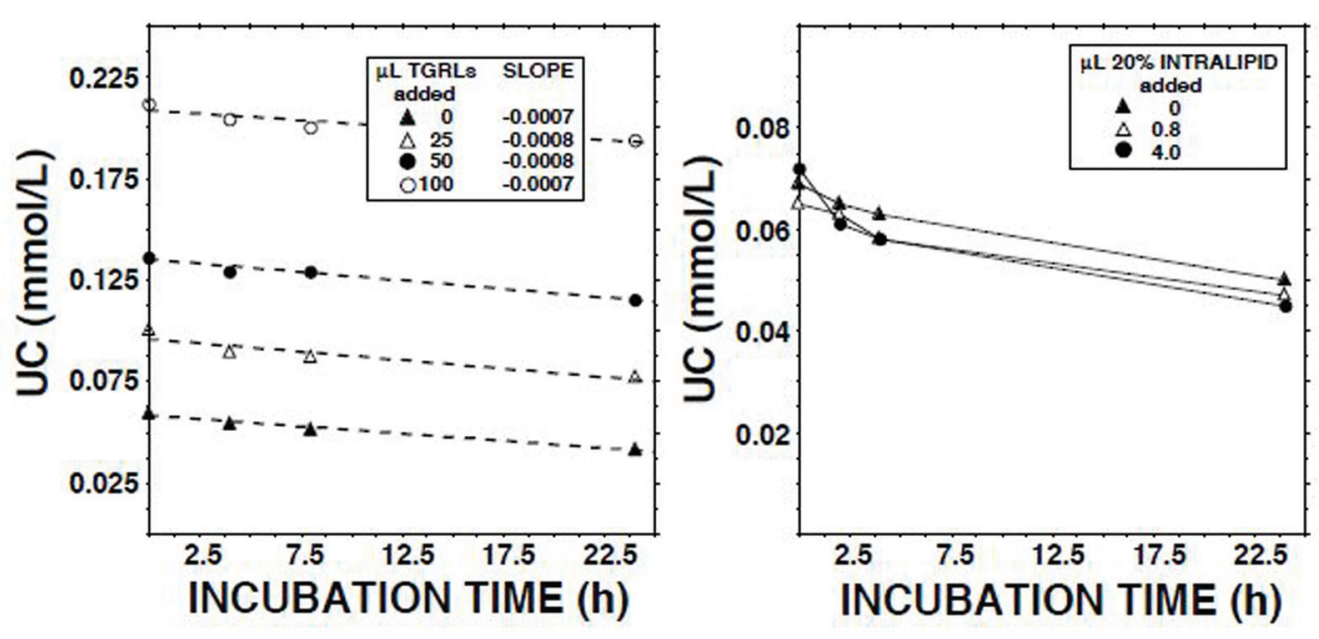

FIGURE 4 | Effects on the unesterified cholesterol concentration (Nanjee and Miller, 1996) in lymph during $22.5 \mathrm{~h}$ of adding Intralipid $20 \%$ (Fresenius Kabi, Clayton, NC; containing $200 \mathrm{~g}$ soybean oil/l; right panel) or the $d<1.006 \mathrm{~g} / \mathrm{ml}$ fraction of fasted normal human plasma (plasma triglycerides, $1.4 \mathrm{mmol} / \mathrm{l})$.

showing that LCAT concentration was not the rate-limiting factor.

No evidence was obtained for a soluble inhibitor of LCAT in lymph. First, when lymph was added to plasma, the ECER was not reduced relative to that observed in plasma alone. Second, when increasing concentrations of recombinant human LCAT were added to lymph, the increments in enzyme activity were similar to those observed when the same masses of LCAT were 


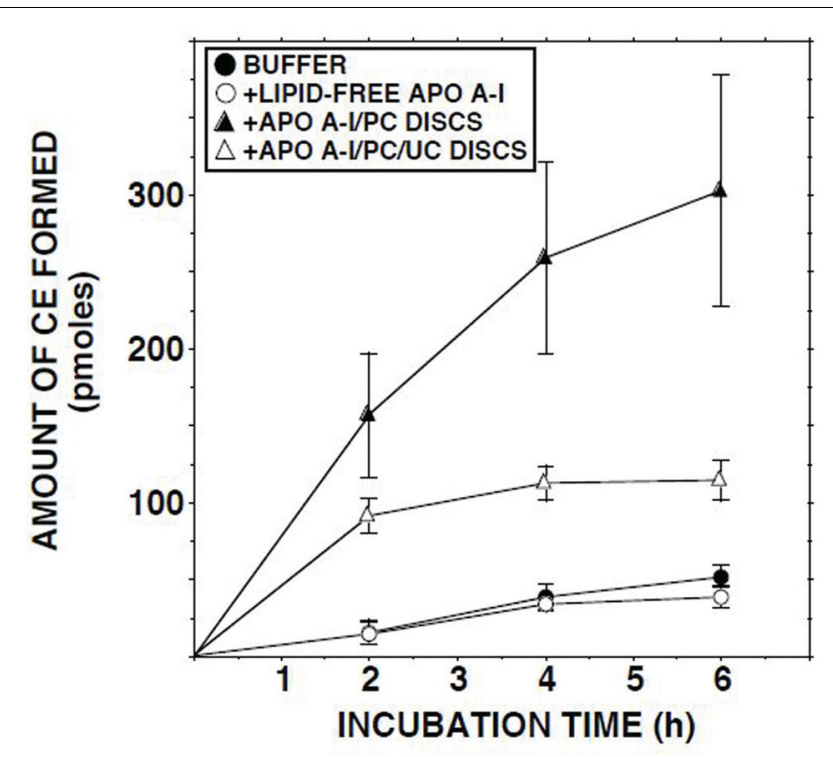

FIGURE 5 | ECER in lymph samples from five subjects as a function of time following addition of Tris-buffered saline, fatty acid-free albumin (final conc $50 \mathrm{mg} / \mathrm{ml}$ ), apo Al/PC disks (1:150 molar ratio; final conc $0.66 \mathrm{mg}$ apo $\mathrm{Al} / \mathrm{ml})$, or apo $\mathrm{Al} / \mathrm{PC} / \mathrm{UC}$ disks (1:150:10, final conc $\mathbf{0 . 6 6} \mathbf{~ m g}$ apo $\mathbf{A l} / \mathbf{m l}$ ). Each incubation mixture was composed of $100 \mu \mathrm{l}$ lymph or Tris-buffered saline plus $100 \mu \mathrm{l}$ of buffer or the test material. At the end of the incubation, $10 \mu$ l aliquots were analyzed in duplicate for UC mass (Nanjee and Miller, 1996). The disks were provided by Central Laboratory, Swiss Red Cross, Bern, Switzerland. Results are means and SEM.

added to normal, heat-inactivated, or LCAT-deficient human plasma.

The much lower concentration of UC in lymph than in plasma raised the question of whether it was limiting the ECER. However, this hypothesis was not compatible with the fact that the lymph/plasma ratio in ECER was much lower than that in UC concentration.

Thus, our evidence suggested that the low esterification rate in lymph HDLs is owing to a property that renders them a poor substrate for LCAT. This hypothesis was supported by the finding that the initial ECER in lymph was increased 10-fold when apo AI/PC disks were added. By contrast, we have previously reported that addition of similar disks to plasma had no effect on ECER (Nanjee et al., 1999). We cannot determine from our data whether the additional esterification in lymph occurred in the disks or the lymph HDLs. LCAT exists in association with HDLs, and the affinity of discoidal HDLs for the enzyme exceeds that of spheroidal CE-rich HDLs (Kosek et al., 1999). The catalytic efficiency of LCAT is also normally greater on discoidal HDLs (Kosek et al., 1999). Thus, it is likely that some UC and LCAT moved from the lymph HDLs to the disks, followed by esterification of UC on the disks. A similar sequence may explain the esterification observed when lymph was mixed with heatinactivated plasma, the lymph HDLs acting as a donor of active LCAT to drive the reaction in plasma HDLs. An alternative possibility is that the disks (or plasma HDLs in the case of heat-inactivated plasma) have a greater affinity for a dissociable inhibitor of LCAT than lymph HDLs, thereby 'cleansing' the latter and enabling the reaction to proceed. Theoretical possibilities for inhibitors include oxidized lipids (Bielicki et al., 1996; Kamiyama et al., 1998) and lysophosphatidylcholine (Smith and Kuksis, 1980). However, the failure of delipidated apo AI and fatty acid-free albumin, which bind oxidized lipids and lysophosphatidylcholine (Navab et al., 2000; Ek-Von Mentzer et al., 2001; Matsumoto et al., 2007), to produce even a small increase in ECER argues against these possibilities.

As LCAT is inhibited by CEs (Fielding and Fielding, 1981), the hypothesis was tested that the ECER in lymph is suppressed by retention of CEs in HDLs secondary to the very low concentrations of apo B-containing lipoproteins. While this seemed unlikely given that lymph HDLs have a greater UC/CE ratio and lower CE/apo AI ratio than plasma HDLs (Nanjee et al., 2000b, 2001), the possibility remained that it was a contributing factor in some HDL subclasses. However, the failure of the $d<1.006$ fraction to increase the ECER despite the presence of CETP in lymph (Miller et al., 2013), albeit in low concentration, argued against this mechanism.

The possibility that esterification in lymph HDLs is suppressed by sphingomyelin, which inhibits LCAT (Bolin and Jonas, 1996), also merits consideration, as the sphingomyelin/PC molar ratio is greater in lymph than in plasma (Nanjee et al., 2000b). However, the difference in ratio ( 0.33 vs. 0.28 ; Nanjee et al., 2000b) appears too small to explain such a large difference in ECER.

On the basis of studies of apo AI epitopes in suction blister fluid, Wong et al. (1992) concluded that apo AI in interstitial fluid does not function as a cofactor for LCAT owing to a change in conformation. This explanation would be compatible with some of our findings. For it to be correct, however, the same change in conformation would need to involve all HDL subclasses in lymph: CE-rich alpha HDLs, lipid-poor pre-beta HDLs, and discoidal HDLs (Nanjee et al., 2000a, 2001; Miller et al., 2013). This would be surprising given that the conformation of apo AI already differs among them. This mechanism would also not explain why apos E and AIV, both of which are present in lymph (Nanjee et al., 2000b) and have cofactor activity for LCAT (Bisgaier et al., 1987; Gong et al., 1989; Emmanuel et al., 1994), do not maintain esterification. The possibility exists that the findings of Wong et al. (1992) were due to tissue disruption and release of proteases during production of the blisters.

In contrast to the apo AI/PC disks, we found that disks with the same apo AI/PC ratio that also contained UC were much less effective in raising ECER. This would be consistent with suppression of cholesterol esterification in lymph HDLs being due to substrate inhibition. Substrate inhibition of LCAT at high $\mathrm{UC} / \mathrm{PC}$ ratios in HDLs, achieved by exposure to phospholipase A2 (Chollet et al., 1986) or enrichment with UC (Simard et al., 1989), has been observed in vitro. In studies with sonicated dispersions of UC and PC, Nichols and Gong (1971) also found that net esterification and initial reaction rate decreased with increasing UC/PC ratio.

Thus, our findings suggest that esterification of UC in interstitial fluid HDLs is suppressed as a consequence of substrate inhibition by UC transferred from cells via ABCA1 transporters. When lymph HDLs enter blood via the lymphatic vessels, the UC 
redistributes among plasma lipoproteins, thereby reducing the inhibition and enabling esterification to proceed.

It is interesting to speculate on the function of substrate inhibition in interstitial fluid. Kinetic analyses of apo AI after intravenous apo AI/PC disks have indicated that HDLs remain in the extracellular matrix on average for about $29 \mathrm{~h}$ before entering the lymph vessels (Hovorka et al., 2006). Lymph is virtually devoid of TGRLs (Nanjee et al., 2000b, 2001), the principal recipients in plasma of CEs transferred via CETP from HDLs. Thus, if UC delivered to HDLs from cells via ABCA1 transporters were continuously esterified, the increase in the size of the particles consequent upon retention of CEs might impede their passage through the interstices of the matrix. An alternative or additional function might be to limit the production of lysophosphatidylcholine in the presence of albumin concentrations that are only one third of those in plasma (Nanjee et al., 2000b), thereby protecting tissues from its detergent and pro-inflammatory activities (Matsumoto et al., 2007).

Our experiments used lymph collected from a vessel that drains skin, connective tissue, and adipose tissue. As other investigators have shown that reverse cholesterol transport from arterial wall macrophages also occurs via lymphatic vessels (Lim et al., 2013; Martel et al., 2013), our findings have implications for strategies to prevent atherosclerosis by modulation of HDL metabolism. If LCAT is inhibited upon entering interstitial fluid in the artery wall, raising its concentration in plasma pharmacologically or by intravenous infusion might not increase efflux of UC from arterial macrophages, its effect being limited to cells exposed directly to plasma (e.g., erythrocytes, liver

\section{REFERENCES}

Alam, K., Meidell, R. S., and Spady, D. K. (2001). Effect of up-regulating individual steps in the reverse cholesterol transport pathway on reverse cholesterol transport in normolipidemic mice. J. Biol Chem. 276, 15641-15649. doi: 10.1074/jbc.M010230200

Albers, J. J., Chen, C. H., and Lacko, A. G. (1986). Isolation, characterization, and assay of lecithin:cholesterol acyltransferase. Methods Enzymol. 129, 763-783. doi: 10.1016/0076-6879(86)29103-X

Bérard, A. M., Föger, B., Remaley, A., Shamburek, R., Vaisman, B. L., Talley, G., et al. (1997). High plasma HDL concentrations associated with enhanced atherosclerosis in transgenic mice overexpressing lecithin-cholesteryl acyltransferase. Nat. Med. 3, 744-749. doi: 10.1038/nm0797-744

Bielicki, J. K., Forte, T. M., and McCall, M. R. (1996). Minimally oxidized LDL is a potent inhibitor of lecithin:cholesterol acyltransferase activity. J. Lipid Res. 37, 1012-1021.

Bisgaier, C. L., Sachev, O. M., Lee, E. S., Williams, K. J., Blum, C. B., and Glickman, R. M. (1987). Effect of lecithin:cholesterol acyltransferase on distribution of apolipoprotein A-IV among lipoproteins of human plasma. J. Lipid Res. 28, 693-703.

Bolin, D. J., and Jonas, A. (1996). Sphingomyelin inhibits the PC-cholesterol acyltransferase reaction with reconstituted high density lipoproteins by decreasing enzyme binding. J. Biol. Chem. 271, 19152-19158. doi: 10.1074/jbc.271.32.19152

Brousseau, M. E., Kauffman, R. D., Herderick, E. E., Demosky, S. J., Evans, W., Marcovina, S., et al. (2000). LCAT modulates atherogenic plasma lipoproteins and the extent of atherosclerosis only in the presence of normal LDL receptors in transgenic rabbits. Arterioscler. Thromb. Vasc. Biol. 20, 450-458. doi: 10.1161/01.ATV.20.2.450

Chajek, T., Aron, L., and Fielding, C. J. (1980). Interaction of lecithin:cholesterol acyltransferase and cholesteryl ester transfer protein in the transport of macrophages, spleen cells). This might explain why LCAT transgenesis has failed to protect mice from atherosclerosis (Bérard et al., 1997; Föger et al., 1999). Brousseau et al. (2000) found that LCAT transgenesis also had no effect on atherosclerosis in LDL receptor negative rabbits. Although it did reduce lesions in cholesterol-fed LDL receptor positive rabbits, this was dependent on an associated reduction of LDL concentration. Van Craeyveld et al. (2009) observed no significant effect of hepatocyte-directed adenoviral rabbit LCAT gene transfer on atherosclerosis in cholesterol-fed rabbits.

\section{AUTHOR CONTRIBUTIONS}

NM conceived and organized the study and was the PI, contributed to the interpretation of the results, and wrote the first draft of the manuscript. WO performed the lymph vessel cannulations, and contributed to the writing of the manuscript. IM undertook the statistical analysis of the data, contributed to their interpretation, and contributed to the preparation of the manuscript. MN designed the laboratory experiments, performed all the experiments and assays, and contributed to the writing of the manuscript.

\section{FUNDING}

This study was funded by grants from the British Heart Foundation, Wellcome Trust and Royal Society.

cholesteryl ester into sphingomyelin liposomes. Biochemistry 19, 3673-3677. doi: 10.1021/bi00557a006

Chollet, F., Perret, B. P., Chap, H., and Douste-Blazy, L. (1986). Phospholipase A2treated human high-density lipoprotein and cholesterol movements: exchange processes and lecithin: cholesterol acyltransferase reactivity. Biochim. Biophys. Acta 875, 135-146. doi: 10.1016/0005-2760(86)90162-1

Cooke, C. J., Nanjee, M. N., Stepanova, I. P., Olszewski, W. L., and Miller, N. E. (2004). Variations in lipid and apolipoprotein concentrations in human leg lymph: effects of posture and physical exercise. Atherosclerosis 173, 39-45. doi: 10.1016/j.atherosclerosis.2003.07.004

Dory, L., Sloop, C. H., Boquet, L. M., Hamilton, R. L., and Roheim, P. S. (1983). lecithin: cholesterol acyltransferase-mediated modification of discoidal peripheral lymph high density lipoproteins: possible mechanism of formation of cholesterol-induced high density lipoproteins (HDLc) in cholesterol-fed dogs. Proc. Natl. Acad. Sci. U.S.A. 80, 3489-3493. doi: 10.1073/pnas.80.11. 3489

Ek-Von Mentzer, B. A., Zhang, F., and Hamilton, J. A. (2001). Binding of 13-HODE and 15-HETE to phospholipid bilayers, albumin, and intracellular fatty acid binding proteins. implications for transmembrane and intracellular transport and for protection from lipid peroxidation. J. Biol. Chem. 276, 15575-15580. doi: 10.1074/jbc.M011623200

Emmanuel, F., Steinmetz, A., Rosseneu, M., Brasseur, R., Gosselet, N., Attentot, F., et al. (1994). Identification of specific amphipathic $\alpha$-helical sequence of human apolipoprotein A-IV involved in lecithin:cholesterol acyltransferase activation. J. Biol. Chem. 269, 29883-29890.

Fielding, C. J., and Fielding, P. E. (1981). Regulation of human plasma lecithin:cholesterol acyltransferase activity by lipoprotein acceptor cholesteryl ester content. J. Biol. Chem. 256, 2102-2104.

Fielding, C. J., Shore, V. G., and Fielding, P. E. (1972). A protein cofactor of lecithin:cholesterol acyltransferase. Biochem. Biophys. Res. Commun. 46, $1493-$ 1498. doi: 10.1016/0006-291X(72)90776-0 
Föger, B., Chase, M., Amar, M. J., Vaisman, B. L., Shamburek, R. D., Paigen, B., et al. (1999). Cholesteryl ester transfer protein corrects dysfunctional high density lipoproteins and reduces aortic atherosclerosis in lecithin cholesterol acyltransferase transgenic mice. J. Biol. Chem. 274, 36912-36920. doi: $10.1074 /$ jbc. 274.52 .36912

Glomset, J. A. (1970). Physiological role of lecithin-cholesterol acyltransferase. Am. J. Clin. Nutr. 23, 1129-1136.

Glomset, J. A., Janssen, E. T., Kennedy, R., and Dobbins, J. (1966). Role of plasma lecithin:cholesterol acyltransferase in the metabolism of high density lipoproteins. J. Lipid Res. 7, 638-648.

Glomset, J. A., Mitchell, C. D., King, W. C., Applegate, K. A., Forte, T., Norum, K. R., et al. (1980). In vitro effects of lecithin:cholesterol acyltransferase on apolipoprotein distribution in familial lecithin:cholesterol acyltransferase deficiency. Ann. N. Y. Acad. Sci. 348, 224-243. doi: 10.1111/j.17496632.1980.tb21303.x

Glomset, J. A., and Norum, K. R. (1973). The metabolic role of lecithin: cholesterol acyltransferase: perspectives from pathology. Adv. Lipid Res. 11, 1-65.

Glomset, J. A., Norum, K. R., and King, W. (1970). Plasma lipoproteins in familial lecithin: cholesterol acyltransferase deficiency: lipid composition and reactivity in vitro. J. Clin. Invest. 49, 1827-1837. doi: 10.1172/JCI106400

Gong, E. L., Nichols, A. V., Weisgraber, K. H., Forte, T. M., Shore, V. G., and Blanche, P. J. (1989). Discoidal complexes containing apolipoprotein E and their transformation by lecithin-cholesterol acyltransferase. Biochim. Biophys. Acta 1006, 317-328. doi: 10.1016/0005-2760(89)90019-2

Hamilton, R. L., Williams, M. C., Fielding, C. J., and Havel, R. J. (1976). Discoidal bilayer structure of nascent high density lipoproteins from perfused rat liver. J. Clin. Invest. 58, 667-680. doi: 10.1172/JCI108513

Hovorka, R., Nanjee, M. N., Cooke, C. J., Miller, I. P., Olszewski, W. L., and Miller, N. E. (2006). Mass kinetics of apolipoprotein A-I in interstitial fluid after administration of intravenous apolipoprotein A-I/lecithin discs in humans. J. Lipid Res. 47, 975-981. doi: 10.1194/jlr.M500358-JLR200

Kamiyama, S., Yamato, T., and Furukawa, Y. (1998). Inhibitory effects of lipid oxidation on the activity of plasma lecithin-cholesterol acyltransferase. Biosci. Biotechnol. Biochem. 62, 941-946. doi: 10.1271/bbb.62.941

Kobori, K., Saito, K., Ito, S., Kotani, K., Manabe, M., and Kanno, T. (2002). A new enzyme-linked immunosorbent assay with two monoclonal antibodies to specific epitopes measures human lecithin-cholesterol acyltransferase. J. Lipid Res. 43, 325-334.

Kosek, A. B., Durbin, D., and Jonas, A. (1999). Binding affinity and reactivity of lecithin cholesterol acyltransferase with native lipoproteins. Biochem. Biophys. Res. Commun. 258, 548-551. doi: 10.1006/bbrc.1999.0690

Lambert, G., Sakai, N., Vaisman, B. L., Neufeld, E. B., Marteyn, B., Chan, C. C., et al. (2001). Analysis of glomerulosclerosis and atherosclerosis in lecithin cholesterol acyltransferase-deficient mice. J. Biol. Chem. 276, 15090-15098. doi: 10.1074/jbc.M008466200

Lim, H. Y., Thiam, C. H., Yeo, K. P., Bisoendial, R., Hii, C. S., McGrath, K. C., et al. (2013). Lymphatic vessels are essential for the removal of cholesterol from peripheral tissues by SR-BI-mediated transport of HDL. Cell Metab. 17, 671-684. doi: 10.1016/j.cmet.2013.04.002

Martel, C., Li, W., Fulp, B., Platt, A. M., Gautier, E. L., Westerterp, M., et al. (2013). Lymphatic vasculature mediates macrophage reverse cholesterol transport in mice. J. Clin. Invest. 123, 1571-1579. doi: 10.1172/JCI63685

Matsumoto, T., Kobayashi, T., and Kamata, K. (2007). Role of lysophosphatidylcholine (LPC) in athersosclerosis. Curr. Med. Chem. 14, 3209-3220. doi: 10.2174/092986707782793899

Michel, C. C., and Curry, F. E. (1999). Microvascular permeability. Physiol. Rev. 79, 703-761.

Miller, K. R., Wang, J., Sorci-Thomas, M., Anderson, R. A., and Parks, J. S. (1996). Glycosylation structure and enzyme activity of lecithin:cholesterol acyltransferase from human plasma, HepG2 cells, and baculoviral and Chinese hamster ovary cell expression systems. J. Lipid Res. 37, 551-561.

Miller, N. E., Olszewski, W. L., Hattori, H., Miller, I. P., Kujiraoka, T., Oka, T., et al. (2013). Lipoprotein remodeling generates lipid-poor apolipoprotein A-I particles in human interstitial fluid. Am. J. Physiol. Endocrinol. Metab. 304, E321-E328. doi: 10.1152/ajpendo.00324.2012

Nanjee, M. N., Cooke, C. J., Olszewski, W. L., and Miller, N. E. (2000a). Concentrations of electrophoretic and size subclasses of apolipoprotein A-I-containing particles in human peripheral lymph. Arterioscler. Thromb. Vasc. Biol. 20, 2148-2155. doi: 10.1161/01.ATV.20.9.2148
Nanjee, M. N., Cooke, C. J., Olszewski, W. L., and Miller, N. E. (2000b). Lipid and apolipoprotein concentrations in prenodal leg lymph of fasted humans. Associations with plasma concentrations in normal subjects, lipoprotein lipase deficiency, and LCAT deficiency. J. Lipid Res. 41, 1317-1327.

Nanjee, M. N., Cooke, C. J., Wong, J. S., Hamilton, R. L., Olszewski, W. L., and Miller, N. E. (2001). Composition and ultrastructure of size subclasses of normal human peripheral lymph lipoproteins: quantification of cholesterol uptake by HDL in tissue fluids. J. Lipid Res. 42, 639-648.

Nanjee, M. N., Doran, J. E., Lerch, P. G., and Miller, N. E. (1999). Acute effects of intravenous infusion of ApoA1/phosphatidylcholine discs on plasma lipoproteins in humans. Arterioscler. Thromb. Vasc. Biol. 19, 979-989. doi: 10.1161/01.ATV.19.4.979

Nanjee, M. N., and Miller, N. E. (1996). Sequential microenzymatic assay of cholesterol, triglycerides, and phospholipids in a single aliquot. Clin. Chem. 42, 915-926.

Nanjee, M. N., Stocks, J., Cooke, C. J., Molhuizen, H. O., Marcovina, S., Crook, D., et al. (2003). A novel LCAT mutation (Phe382 > Val) in a kindred with familial LCAT deficiency and defective apolipoprotein B-100. Atherosclerosis 170, 105-113. doi: 10.1016/S0021-9150(03) 00241-7

Navab, M., Hama, S. Y., Cooke, C. J., Anantharamaiah, G. M., Chadha, M., Jin, L., et al. (2000). Normal high density lipoprotein inhibits three steps in the formation of mildly oxidized low density lipoprotein: step 1. J. Lipid Res. 41, 1481-1494.

Nichols, A. V., and Gong, E. L. (1971). Use of sonicated dispersions of mixtures of cholesterol with lecithin as substrates for lecithin:cholesterol acyltransferase. Biochim. Biophys. Acta 231, 175-184. doi: 10.1016/0005-2760(71)90266-9

Oram, J. F., and Heinecke, J. W. (2005). ATP-binding cassette transporter A1: a cell cholesterol exporter that protects against cardiovascular disease. Physiol. Rev. 85, 1343-1372. doi: 10.1152/physrev.00005.2005

Reichl, D., Myant, N. B., Rudra, D. N., and Pflug, J. J. (1980). Evidence for the presence of tissue-free cholesterol in low density and high density lipoproteins of human peripheral lymph. Atherosclerosis 37, 489-495. doi: 10.1016/00219150(80)90156-2

Simard, G., Loiseau, D., Girault, A., and Perret, B. (1989). Reactivity of HDL subfractions towards lecithin-cholesterol acyltransferase. Modulation by their content in free cholesterol. Biochim. Biophys. Acta 1005, 245-252. doi: 10.1016/0005-2760(89)90044-1

Smith, N. B., and Kuksis, A. (1980). Stereochemical substrate requirements of lecithin:cholesterol acyltransferase and its inhibition by enantiomeric lysolecithins. Can. J. Biochem. 58, 1286-1291. doi: 10.1139/o80-172

Stokke, K. T., Bjerve, K. S., Blomhoff, J. P., Oystese, B., Flatmark, A., Norum, K. R., et al. (1974). Familial lecithin:cholesterol acyltransferase deficiency. Studies on lipid composition and morphology of tissues. Scand. J. Clin. Lab. Invest. Suppl. 137, 93-100. doi: 10.1080/00365517409100636

Tanigawa, H., Billheimer, J. T., Tohyama, J., Fuki, I. V., Ng, D. S., Rothblat, G. H., et al. (2009). lecithin: cholesterol acyltransferase expression has minimal effects on macrophage reverse cholesterol transport in vivo. Circulation 120, 160-169. doi: 10.1161/CIRCULATIONAHA.108.825109

Van Craeyveld, E., Lievens, J., Jacobs, F., Feng, Y., Snoeys, J., and De Geest, B. (2009). Apolipoprotein A-I and lecithin:cholesterol acyltransferase transfer induce cholesterol unloading in complex atherosclerotic lesions. Gene Ther. 16, 757-765. doi: $10.1038 /$ gt.2009.8

Wong, L., Curtiss, L. K., Huang, J., Mann, C. J., Maldonado, B., and Roheim, P. S. (1992). Altered epitope expression of human interstitial fluid apolipoprotein A-I reduces its ability to activate lecithin cholesterol acyl transferase. J. Clin. Invest. 90, 2370-2375. doi: 10.1172/JCI116127

Conflict of Interest Statement: The authors declare that the research was conducted in the absence of any commercial or financial relationships that could be construed as a potential conflict of interest.

Copyright (C) 2016 Miller, Olszewski, Miller and Nanjee. This is an open-access article distributed under the terms of the Creative Commons Attribution License (CC BY). The use, distribution or reproduction in other forums is permitted, provided the original author(s) or licensor are credited and that the original publication in this journal is cited, in accordance with accepted academic practice. No use, distribution or reproduction is permitted which does not comply with these terms. 